\title{
Kolbe Anodic Decarboxylation as a Green Way To Access 2-Pyrrolidinones
}

\author{
Mathilde Quertenmont, Iain Goodall, Kevin Lam,* István Markó, and Olivier Riant* \\ Cite This: https://dx.doi.org/10.1021/acs.orglett.0c00056 \\ Read Online
}

ACCESS |

Lلll Metrics \& More

Article Recommendations

Supporting Information

ABSTRACT: Nootropic compounds are a group of pharmacologically active pyrrolidones. These molecules, which enhance cognition properties and possess a large prescription field, are particularly interesting synthetic targets for the pharmaceutical industry. In this Article, we disclose an effective and environmentally friendly pyrrolidinone synthesis using electrosynthesis. The newly developed methodology includes a Kolbe decarboxylation, followed by an intramolecular radical cyclization and a radical-radical cross-coupling.

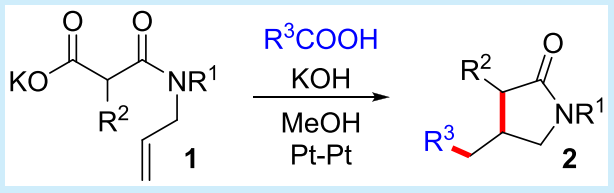

Tootropic compounds are a group of pharmacologically 1 active pyrrolidones. These molecules, which enhance cognition properties and possess a large prescription field, are particularly interesting synthetic targets for the pharmaceutical industry. ${ }^{2}$ Synthetic organic electrochemistry takes its roots from the classic works of Faraday ${ }^{3}$ and Kolbe $^{4}$ on the electrolysis of aliphatic carboxylic acids. Although numerous transformations have been developed since then, ${ }^{5-9}$ and many of them were successfully used in several industrial processes, ${ }^{10,11}$ the potential of preparative organic electrochemistry remains underestimated, even though electrosynthesis represents one of the safest and greenest method to perform organic redox reactions. Hopefully, the new commercially available Electrasyn 2.0 electrolysis setup will facilitate the use of electrosynthesis in organic synthetic laboratories. ${ }^{12}$ The Kolbe anodic decarboxylation is among the oldest and probably the most famous oxidative electro-organic reactions. ${ }^{4}$ This approach enables the environmentally friendly synthesis of long-chain alkanes from short-chain carboxylic acids, in three steps. ${ }^{13,14}$

Schäfer et al. have previously shown that the electrogenerated radical 5a can undergo radical cyclization and that the final cyclic radical $\mathbf{6 a}$ could be trapped by radicals generated by the anodic decarboxylation of a coacid present in excess. An excess of the coacid is used in order to prevent the homocoupling of substrate 6a. Unfortunately, the yields in cyclic compounds 7 a remains modest (see Scheme 1). ${ }^{15}$

Our group has showed formerly that the presence of an electron-withdrawing substituent on the $\mathrm{C}-\mathrm{C}$ double bound dramatically increases the yield of the desired cyclic compounds $7 \mathbf{b}$ since the electrodeficient double bond is a better coupling partner for the nucleophilic electrogenerated radical (see Scheme 1). ${ }^{16}$ It also stabilizes the cyclic radical.

In this Article, we will describe a new, original, and environmentally friendly electrosynthesis of pyrrolidinones of pharmaceutical interest (see Scheme 2). This process expands
Scheme 1. Proposed Mechanistic Sequence: Kolbe Decarboxylation-Radical Cyclization-Radical Capture

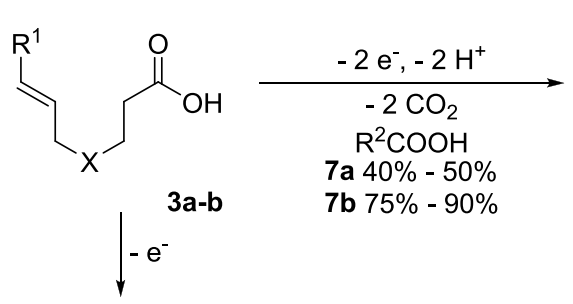<smiles>[R]C([R])C1CCC[Y]1([Y6])C(=O)O</smiles>

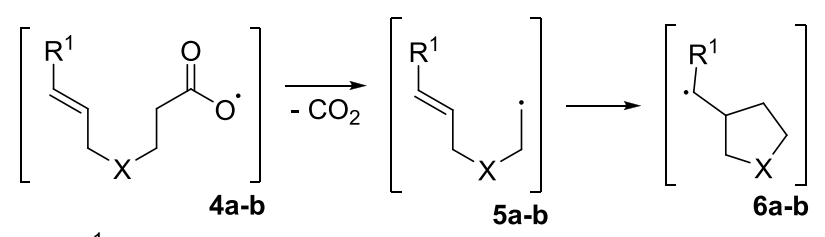

3-7a R ${ }^{1}=\mathrm{H}-\mathrm{X}=\mathrm{CH}_{2}, \mathrm{O}, \mathrm{NR}$

3-7b R ${ }^{1}=$ ester, nitrile, amide $-\mathrm{X}=\mathrm{CH}_{2}$, O

the scope of the synthetic applications of the Kolbe electrocyclization reaction.

At the outset of this investigation, compounds $\mathbf{8 a - 8 d}$ were synthesized in a straightforward manner, according to the sequence outlined in the Supporting Information. Potassium salts $(\mathbf{8} \mathbf{a}-\mathbf{8 d})$ were used as the substrates of the electrocyclization, because of the instability of the corresponding carboxylic acids. ${ }^{17}$ The amide group was functionalized with various groups, such as allyl, benzyl, isopropyl, or neopentyl, to avoid the amide function oxidation under the electrolytic conditions. $^{18}$ For instance, the allyl and benzyl protecting

Received: January 6, 2020 
Scheme 2. Electrosynthesis of Pyrrolidones<smiles>[R]C(C(=O)O)C(=O)N([R])CC=C</smiles><smiles>[R]CC1CN([R17])C(=O)C1[R]</smiles><smiles>[3H][3H]</smiles>
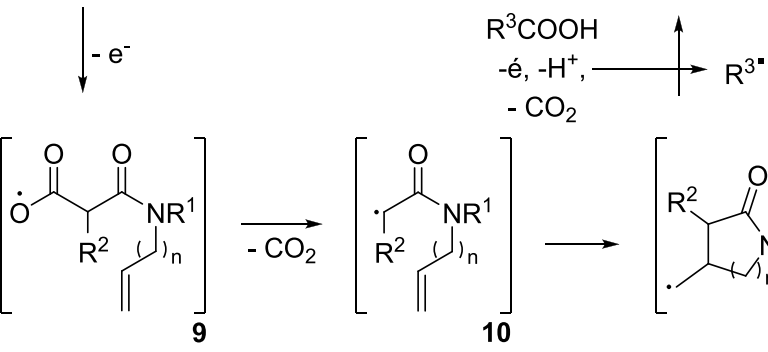
$-\mathrm{CO}_{2}$

$\mathrm{n}=1,2$

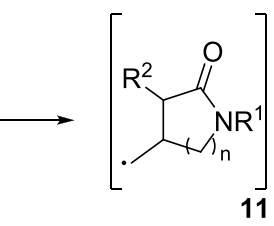

groups could easily be deprotected or further functionalized after the oxidative reaction, opening the way to more chemical diversity, which is especially important for drug design. ${ }^{19,20}$

With the desired precursors in hand, the electrolysis parameters were optimized (see Table 1). Bulk electrolysis that has been performed using previously reported conditions led to the formation of the desired pyrrolidones in very modest yields. ${ }^{3}$ In order to avoid homocoupling of the radical 11, the substrate should be highly diluted in methanol $(66 \mathrm{mM}$ in methanol), and the current density, which is a key parameter, should be kept between $25 \mathrm{~mA} / \mathrm{cm}^{2}$ and $37.5 \mathrm{~mA} / \mathrm{cm}^{2}$. In addition, a temperature between $10{ }^{\circ} \mathrm{C}$ and $20{ }^{\circ} \mathrm{C}$, the use of smooth platinum electrodes, and an excess of coacid ( 5 equiv) provided the optimum results. Finally, the use of 5 equiv of supporting electrolyte $(\mathrm{KOH})$ avoided the decarboxylation of the substrate by maintaining basic conditions.

With the optimized conditions ready, the scope and limitation of the methodology were investigated (see Table 2 ). The variation of the coacid nature allowed the synthesis of several pyrrolidinones substituted in position 4. The substitution of that position has been reported to have a major effect on the biological activity of this class of compounds. ${ }^{2}$ In the presence of acetic acid and propionic acid, the electrocyclization proceeded smoothly and afforded aliphatic pyrrolidinones $12 \mathrm{a}, \mathbf{1 2} \mathrm{b}, \mathbf{1 2} \mathrm{h}$, and $12 \mathrm{j}$ in good yields $(60 \%-71 \%)$. Furthermore, the use of monomethyl hydrogen succinate (13f), ethyl potassium malonate (13e), and 4acetylbutyric acid (13g) as coacids also enables the formation of pyrrolidinones $12 \mathrm{e}, \mathbf{1 2 f}, \mathbf{1 2} \mathrm{g}$, and $\mathbf{1 2} \mathrm{i}$ in good yields. 3,3,3Trifluoropropionic acid (13d) and fluoropropionic acid (13c) allowed the formation of fluorinated pyrrolidinones $12 \mathrm{c}$ and 12d but lower yields are obtained with the latest. This result is due to the higher acidity of the fluoroacetic acid. Besides, comparable yields are obtained in the presence of the four protecting groups, which enables one to produce several $\mathrm{N}$ substituted pyrrolidones $(12 a-12 n)$. In the presence of a benzyl protecting group, there is the formation of the side product $14 \mathrm{a}$, which is generated by the cross-coupling of the radical 10 and the radical which comes from the oxidative decarboxylation of the coacid $\mathbf{1 3 b}$. This phenomenon might be due to the steric hindrance of substrate $\mathbf{8 d}$, which limits the amide $\mathrm{C}-\mathrm{N}$ bond rotation or absorption phenomenon of the benzyl-substituted radicals on the electyrode surface. Finally, in order to expand the scope of this electrocyclization reaction, we applied the optimized conditions to substrate $8 \mathbf{e}$ bearing a homoallyl function. The reaction of substrate $8 \mathrm{e}$ also proceeded smoothly and provided the corresponding 6membered ring product $\mathbf{1 2 1}$. However, as the 6-exo cyclization is known to proceed at a lower speed, compared to 5-exo cyclization, the primary radical $\mathbf{1 0}$ can then dimerize and we observed the formation of the side-product dimer 14c, along with the desired piperidinone.

To broaden the scope of the functionalized pyrrolidinones cyclization, we synthesized the allylic and propargylic substrates $\mathbf{8 f}$ and $\mathbf{8 g}$ in a straightforward manner, according to the sequence outlined in the Supporting Information. The electrocyclization of those substrates allowed the formation of

Table 1. Optimization of the Electrocyclization Reaction
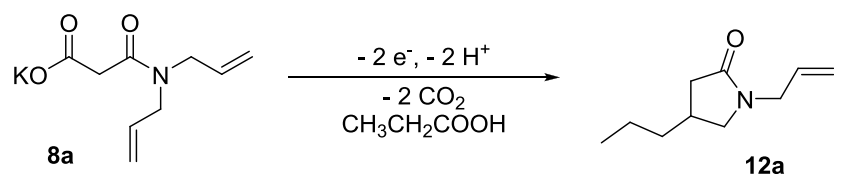

\begin{tabular}{|ccr|}
\hline entry & $C(\mathrm{~mol} / \mathrm{L})$ & current density \\
1 & 0.033 & 25 \\
2 & 0.066 & 25 \\
3 & 0.132 & 12 \\
4 & 0.066 & 25 \\
5 & 0.066 & 5 \\
6 & 0.066 & 25 \\
7 & 0.066 & 25 \\
8 & 0.066 & 25 \\
9 & 0.066 & 25 \\
10 & 0.066 & 25 \\
11 & 0.066 & 25 \\
12 & 0.066 & 25 \\
13 & 0.066 & 25 \\
14 & 0.066 & 25 \\
15 & 0.066 & 25 \\
16 & 0.066 &
\end{tabular}

25
25
25
2,5
25
50
25
25
25
25
25
25
25
25
25
25

temperature, $T\left({ }^{\circ} \mathrm{C}\right)$
10
10
10
10
10
10
0
10
40
10
10
10
10
10
10
10

$\begin{array}{ll}\text { electrodes } & \text { solvent } \\ \text { platinum } & \mathrm{MeOH} \\ \text { platinum } & \mathrm{MeOH} \\ \text { platinum } & \mathrm{MeOH} \\ \text { platinum } & \mathrm{MeOH} \\ \text { platinum } & \mathrm{MeOH} \\ \text { platinum } & \mathrm{MeOH} \\ \text { platinum } & \mathrm{MeOH} \\ \text { platinum } & \mathrm{MeOH} \\ \text { platinum } & \mathrm{MeOH} \\ \text { platinum } & \mathrm{MeOH} \\ \text { platinum } & \mathrm{EtOH} \\ \text { platinum } & \mathrm{CH} C \mathrm{CN} \\ \text { platinum } & \mathrm{MeOH} \\ \text { platinum } & \mathrm{MeOH} \\ \text { platinum } & \mathrm{MeOH} \\ \text { platinum } & \mathrm{MeOH}\end{array}$

$2 a$

$\mathrm{MeOH}$

$\mathrm{MeOH}$

$\mathrm{MeOH}$

$\mathrm{MeOH}$

$\mathrm{MeOH}$

$\mathrm{MeOH}$

$\mathrm{MeOH}$

$\mathrm{MeOH}$

$\mathrm{CH}_{3} \mathrm{CN}$

$\mathrm{MeOH}$

$\mathrm{MeOH}$

$\mathrm{MeOH}$

$\begin{array}{cc}{[\mathrm{KOH}] \text { (equiv) }} & \text { yield (\%) } \\ 5 & 68 \\ 5 & 71 \\ 5 & 26 \\ 5 & 56 \\ 5 & 71 \\ 5 & 64 \\ 5 & 29 \\ 5 & 71 \\ 5 & 37 \\ 5 & 71 \\ 5 & 49 \\ 5 & 70 \\ 5 & 71 \\ 0.05 & 54 \\ 0.33 & 66 \\ 5 & 71\end{array}$


Table 2. Scope and Limitations of Substrates

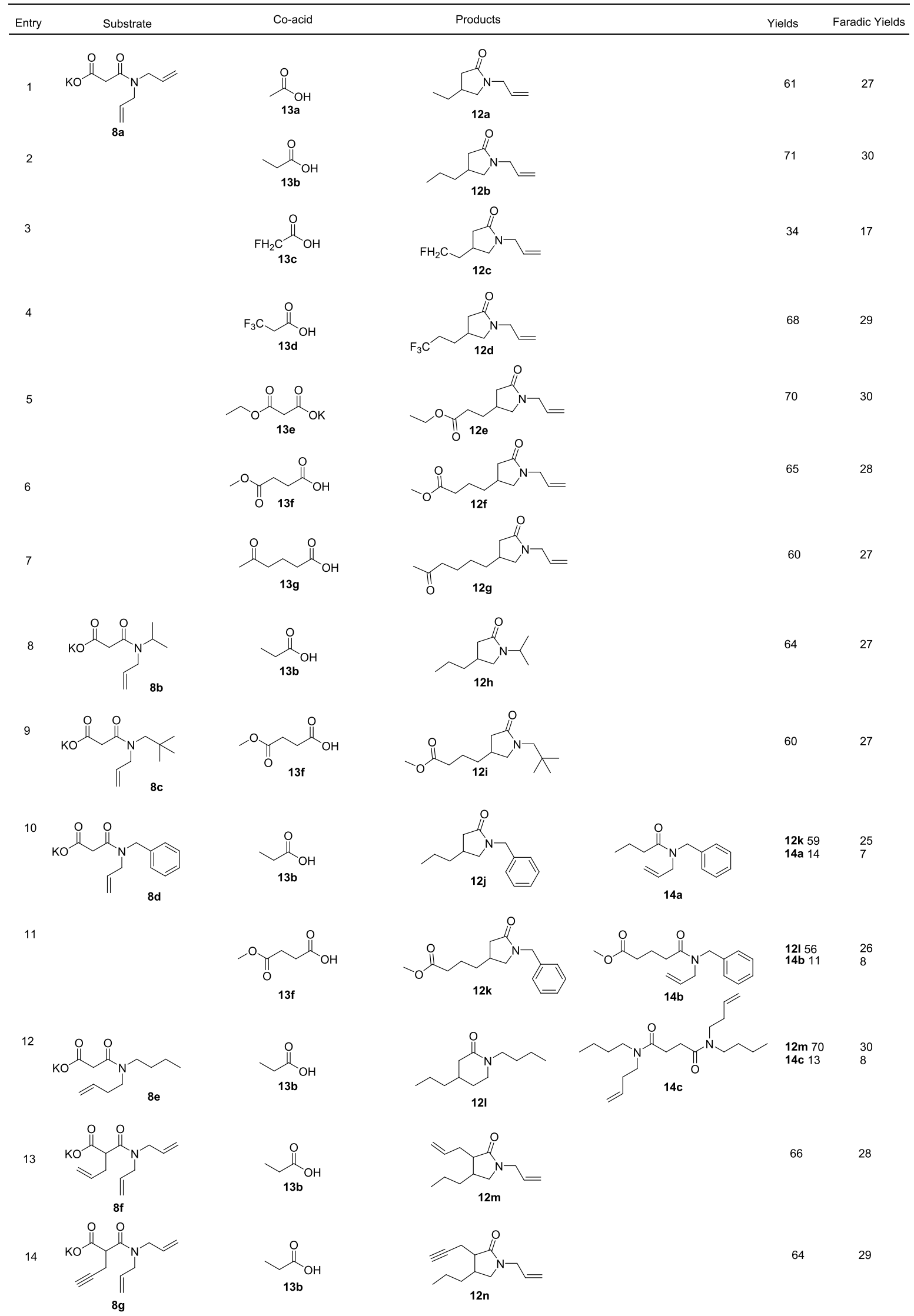


Table 3. Diastereoselective Pyrrolidinone Electrosynthesis

Entry Substrate

the position 5-substituted pyrrolidinones $12 \mathrm{~m}$ and $12 \mathrm{n}$, in $66 \%$ and $64 \%$ yields, respectively.

Because of the importance of being able to control the chirality while developing bioactive molecules, we investigated the possibility to develop a diastereoselective electrocyclization of pyrrolidinones. Our strategy to induce a stereoselectivity during the cyclization was to incorporate a chiral center in the structure of the precursor. With this intention, substrate $\mathbf{1 5}$ was synthesized from the $(R)-(+)-\alpha$-methylbenzylamine. The desired precursor available for use, the electrochemical reaction was performed using the previously optimized conditions. Finally, the product was analyzed by high-performance liquid chromatography-mass spectroscopy (HPLC-MS). Those analyses have showed a good diastereoselective ratio for this electrochemical transformation. As a result, the use of $(R)$ (+)- $\alpha$-methylbenzylamine as chiral inductor has led to the formation of the enantio-enriched pyrrolidinones 16 with a diastereoselective ratio of 96:4 (see Table 3). One of the main advantages of using benzylamine derivatives as chiral inductors is that they can easily be removed after the electrochemical process by catalytic hydrogenation, ${ }^{21}$ catalytic transfer hydrogenation, $^{22}$ and other reactions. ${ }^{23}$

In summary, we have developed methodology for the efficient and environmentally friendly electrochemical synthesis of functionalized pyrrolidinones. Our approach includes a Kolbe decarboxylation, followed by a radical cyclization and, finally, a cross-coupling step between the radical formed and a radical engendered by the concomitant decarboxylation of a coacid. This reaction enables the formation of two carboncarbon bonds in one step. The functional group tolerance of this method proved to be quite broad. Indeed, the electrolysis can be successfully accomplished in the presence of ester, olefin, ketone, halogen, amide, and alkyne functions. Finally, the methodology was successfully transposed toward the synthesis of the stereoenriched pyrrolidinone 16 with a diastereoselective ratio of $96: 4$ by using a chiral inductor group on the precursors. The methodology represents an attractive procedure for the synthesis of diversely functionalized pyrrolidinones.

\section{ASSOCIATED CONTENT}

\section{SI Supporting Information}

The Supporting Information is available free of charge at https://pubs.acs.org/doi/10.1021/acs.orglett.0c00056.

General experimental section; details regarding the synthesis of various compounds used/produced in this work; table of details regarding optimization of the electrocyclization reaction; NMR spectra (PDF)

\section{AUTHOR INFORMATION}

Corresponding Authors

Kevin Lam - Department of Pharmaceutical, Chemical and Environmental Sciences, Faculty of Engineering and Science, University of Greenwich, Chatham Maritime ME4 4TB, United Kingdom; (1) orcid.org/0000-0003-1481-9212;

Email: k.lam@greenwich.ac.uk

Olivier Riant - Institute of Condensed Matter and Nanosciences (IMCN), Molecular Chemistry, Materials and Catalysis (MOST) unit, Université Catholique de Louvain (UCL), 1348 Louvain-la-Neuve, Belgium; 이이이.org/0000-0003-48526469; Email: olivier.riant@uclouvain.be

\section{Authors}

Mathilde Quertenmont - Institute of Condensed Matter and Nanosciences (IMCN), Molecular Chemistry, Materials and Catalysis (MOST) unit, Université Catholique de Louvain (UCL), 1348 Louvain-la-Neuve, Belgium

Iain Goodall - Department of Pharmaceutical, Chemical and Environmental Sciences, Faculty of Engineering and Science, University of Greenwich, Chatham Maritime ME4 4TB, United Kingdom

§István Markó - Institute of Condensed Matter and Nanosciences (IMCN), Molecular Chemistry, Materials and Catalysis (MOST) unit, Universite Catholique de Louvain (UCL), 1348 Louvain-la-Neuve, Belgium

Complete contact information is available at:

https://pubs.acs.org/10.1021/acs.orglett.0c00056

\section{Author Contributions}

The manuscript was written through contributions of all authors. All authors have given approval to the final version of the manuscript.

Notes

The authors declare no competing financial interest.

${ }^{\S}$ Deceased (July 31, 2017).

\section{ACKNOWLEDGMENTS}

Financial support for this research by the Fonds pour la Formation à la Recherche dans l'Industrie et dans l'Agriculture (F.R.I.A.) and the Université Catholique de Louvain are gratefully acknowledged.

\section{REFERENCES}

(1) (a) Giurgea, C. E. Drug Dev. Res. 1982, 2, 441. (b) Giurgea, C.; Salama, M. Prog. Neuro-Psychopharmacol. 1977, 1, 235. (c) Giurgea, C. The "nootropic" approach to the pharmacology of the integrative activity of the brain 1, 2. Conditional Reflex 1973, 8, 108-115 (https://link.springer.com/article/10.1007/BF03000311).

(2) (a) Bhattacharya, K.; Upadhyay, S.; Jaiswal, A.; Bhattacharyla, S. Indian J. Exp. Biol. 1989, 28, 261. (b) Winnocka, K.; Tomasiak, M.; Bielawska, A. Acta Poloniae Pharmaceutica - Drug Research 2005, 62, 
405. (c) Grossman, L.; Stewart, A.; Gaikwad, S.; Utterback, E.; Wu, N.; DiLeo, J.; Frank, K.; Hart, P.; Howard, H.; Kalueff, A. V. Brain Res. Bull. 2011, 85, 58.

(3) Faraday, M. Experimental Researches in Electricity. Philos. Trans. R. Soc. London 1832, 122, 125.

(4) Kolbe, H. Untersuchungen Über Die Elektrolyse Organischer Verbindungen. Justus Liebigs Ann. Chem. 1849, 69, 257.

(5) Hayrapetyan, D.; Shkepu, V.; Seilkhanov, O. T.; Zhanabil, Z.; Lam, K. Electrochemical Synthesis of Phthalides via Anodic Activation of Aromatic Carboxylic Acids. Chem. Commun. 2017, 53, 8451.

(6) Lam, K.; Geiger, W. E. Anodic Oxidation of Disulfides: Detection and Reactions of Disulfide Radical Cations. J. Org. Chem. 2013, 78, 8020 .

(7) Horn, E. J.; Rosen, B. R.; Baran, P. S. Synthetic Organic Electrochemistry: An Enabling and Innately Sustainable Method. ACS Cent. Sci. 2016, 2, 302.

(8) Ma, X.; Luo, X.; Dochain, S.; Mathot, C.; Markò, I. E. Electrochemical Oxidative Decarboxylation of Malonic Acid Derivatives: A Method for the Synthesis of Ketals and Ketones. Org. Lett. 2015, 17, 4690 .

(9) Lam, K.; Marko, I. E.; Lebreux, F.; Luo, X.; Ma, X. Electrochemical Methoxymethylation of Alcohols-A New Green and Safe Approach for the Preparation of MOM Ethers and Other Acetals. Chem. Commun. 2018, 54, 9969-9972.

(10) Organic Electrochemistry: Revised and Expanded, 5th Edition; Hammerich, O., Speiser, B., Eds.; CRC Press: Boca Raton, FL, 2015.

(11) Horn, E. J.; Rosen, B. R.; Chen, Y.; Tang, J.; Chen, K.; Eastgate, M. D.; Baran, P. S. Scalable and Sustainable Electrochemical Allylic C-H Oxidation. Nature 2016, 533, 77.

(12) ElectraSyn 2.0 Package-IKA; available via the Internet at: https: / / www.ika.com/laboratory-equipment/products/ electrochemistry-kit/products/4265/electrasyn-2.0-package (accessed March 19, 2018).

(13) For the preparation of Kolbe dimers, see: (a) Brown, A. C.; Walker, J. Justus Liebigs Ann. Chem. 1891, 261, 107. (b) Fichter, F.; Lurie, S. Helv. Chim. Acta 1933, 16, 885-891.

(14) For Kolbe cross-coupling reactions, see: (a) Seebach, D.; Renaud, P. Helv. Chim. Acta 1985, 68, 2342. (b) Kubota, T.; Aoyagi, R.; Sando, H.; Kawasumi, M.; Tanaka, T. Chem. Lett. 1987, 16, 14351438.

(15) (a) Weiguny, J.; Schäfer, H. J. Electroorganic Synthesis 1994, 1994, 235-242. (b) Matzeit, A.; Schäfer, H.; Amatore, C. Synthesis 1995, 1995, 1432. (c) Garwood, R. F.; Naser-ud-Din; Scott, C. J.; Weedon, B. C. L. J. Chem. Soc., Perkin Trans. 1 1973, 2714.

(16) (a) Lebreux, F.; Buzzo, F.; Markó, I. E. ESC Transactions 2008, 13, 1. (b) Lebreux, F.; Buzzo, F.; Markó, I. E. Synlett 2008, 2008, 2815.

(17) Hall, G. A. J. Am. Chem. Soc. 1949, 71 (8), 2691.

(18) (a) Becking, L.; Schäfer, H. J. Tetrahedron Lett. 1988, 29, 2797. (b) Ole, H.; Lund, H. Organic Electrochemistry, Fourth Edition; Marcel Dekker: New York, 1991.

(19) For the deprotection of the allyl function, see: (a) Alcaide, B.; Almendros, P.; Alonso, J. M. Tetrahedron Lett. 2003, 44 (48), 8693. (b) Cadierno, V.; Gimeno, J.; Nebra, N. Chem. - Eur. J. 2007, 13 (23), 6590.

(20) For the deprotection of the benzyl function, see: (a) Paik, S.; Lee, J. Y. Tetrahedron Lett. 2006, 47, 1813. (b) Rombouts, F.; Franken, D.; Martinez-Lamenca, C.; Braeken, M.; Zavattaro, C.; Chen, J.; Trabanco, A. A. Tetrahedron Lett. 2010, 51, 4815. (c) Ishii, K.; Sugiyama, S.; Morishita, K.; Chiba, M. Heterocycles 2002, 57, 637.

(21) (a) Nikiforov, T.; Stanchev, S.; Milenkov, B.; Dimitrov, V. Heterocycles 1986, 24, 1825. (b) Vazquez, E.; Galindo, A.; Gnecco, D.; Bernes, S. Tetrahedron: Asymmetry 2001, 12, 2099. (c) Tararov, V. I.; Kadyrov, R.; Kadyrova, Z.; Dubrovina, N.; Borner, A. Tetrahedron: Asymmetry 2002, 13, 25. (d) Couture, A.; Deniau, E.; Grandclaudon, P.; lebrun, S. Tetrahedron: Asymmetry 2003, 14, 1309.

(22) (a) Daga, M. C.; Taddei, M.; Varchi, G. Tetrahedron Lett. 2001, 42, 5191. (b) Volk, F.-J.; Wagner, M.; Frahm, A. W. Tetrahedron:
Asymmetry 2003, 14, 497. (c) Meyer, U.; Breitling, E.; Bisel, P.; Frahm, A. W. Tetrahedron: Asymmetry 2004, 15, 2029.

(23) (a) Arvanitis, E.; Motevalli, M.; Wyatt, P. B. Tetrahedron Lett. 1996, 37, 4277. (b) Baussanne, I.; Travers, C.; Royer, J. Tetrahedron: Asymmetry 1998, 9, 797. (c) Paik, S.; Lee. Tetrahedron Lett. 2006, 47, 1813. 